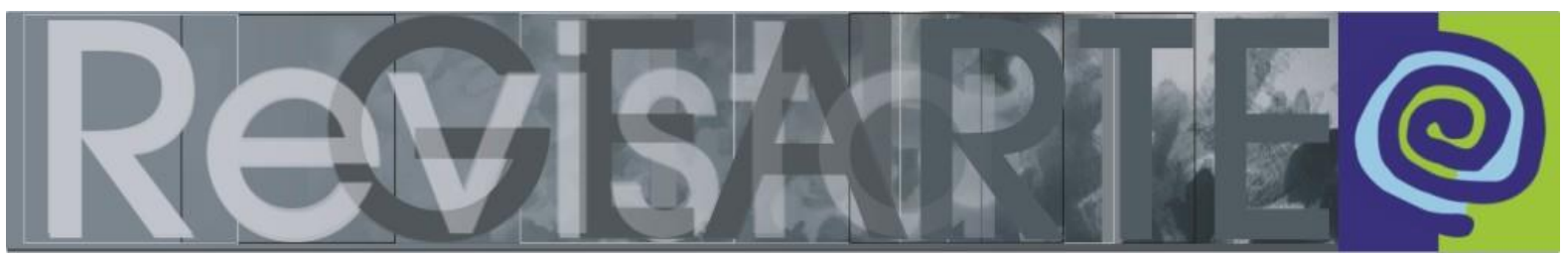

ISSN 2357-9854 | e-ISSN 2596-3198 (online)

\title{
Ensino das Artes Visuais e do Design: abordagens transdisciplinares
}

\section{Entre o Ensino das Artes Visuais e do Design}

Este número temático da Revista GEARTE reúne pesquisas e reflexões ligadas aos desafios do ensino de artes visuais e do design como campos de pesquisas educacionais, abordando análises de recursos metodológicos desenvolvidos e/ou aplicados por professores e pesquisadores das duas áreas em suas práticas cotidianas.

Nas últimas décadas novos cursos de artes visuais e de design foram criados em todo o país, na modalidade tecnológica, acadêmica, ou por meio da educação a distância, cada um deles impondo desafios para que os professores reflitam sobre práticas e abordagens metodológicas adotadas em sala de aula.

Esse contexto nos levou a tecer as seguintes considerações: como se configura a atuação dos profissionais como docentes nos cursos de artes visuais e design? Quais os principais desafios e soluções encontrados por docentes para atuarem nas disciplinas teóricas e práticas em cursos de graduação e pósgraduação? Como os docentes dos cursos de artes visuais e design lidam com a questão da inclusão e diversidade na sala de aula? Como os docentes de artes visuais da Educação Infantil ao Ensino Médio desenvolvem suas práticas pedagógicas?

Perscrutar tais indagações implica na observação do desenvolvimento de novas estratégias e adaptação de abordagens metodológicas para atender às reais condições e possibilidades de ensino/aprendizagem nos diferentes espaços educacionais em que os cursos estão inseridos.

Assim, este número da revista apresenta contribuições de pesquisadores e docentes dos cursos de artes visuais e design de diferentes países que se debruçam sobre os múltiplos saberes e práticas que estabelecem suas identidades profissionais e suas "táticas de resistências". A proposta de replicar as ideias trazidas por De 


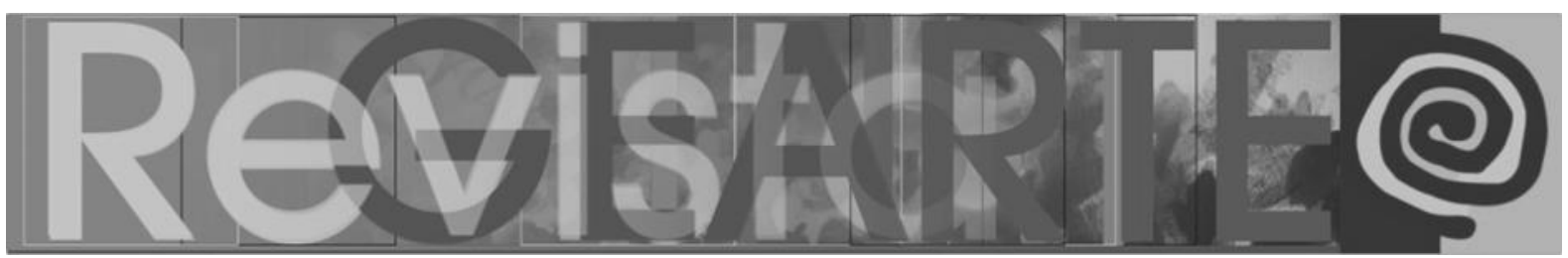

Certeau (1998), nas quais as "maneiras de fazer" expõem as práticas de apropriação dos espaços e das técnicas de produção, refletem as experiências ativas e dinâmicas, os processos de interação entre os seres humanos e o meio, nomeados por Dewey (2010) como experiências.

São publicados além dos sete artigos dedicados ao tema proposto, um ensaio visual e uma homenagem ao arte/educador Arthur Efland.

No artigo Ensino-aprendizagem de desenho: uma proposta transdisciplinar que acolhe o pensamento complexo, Bernardo Bustamante Cardona, professor da Universidad de Antioquia (Medellín, Colombia), discute a necessidade de mudança de paradigma visando propor o pensamento complexo como estratégia para o ensino do desenho. Para tanto, o autor aborda o conceito de complexidade no âmbito da pedagogia e elenca diversos enfoques e tendências de ensino do desenho ao longo do tempo, chegando ao pós-moderno e à cultura visual, culminando com a formulação de uma proposta de ensino baseada na complexidade por meio da criação transdisciplinar.

Ângela Saldanha e Teresa Torres de Eça, professoras da Associação de Professores de Expressão e Comunicação Visual (Viseu, Portugal), em Errar Partilhar-Aprender: o ensino transdisciplinar e holístico através de técnicas das Artes Visuais (experiências em quatro continentes) nos guiam em experiências educacionais e artísticas em que o viajar aparece como um processo introspectivo de/no conhecimento e, por meio da partilha, se torna um método de encontro com o Outro e suas diversidades em quatro continentes diferentes. As autoras constroem uma narrativa plural e holística na qual a imagem tem o mesmo poder que a palavra. Seguindo-as, nos vemos imersos no âmago daquilo a que aprendemos a denominar como educação democrática, diversificada, inclusiva, na qual a voz dos sujeitos estão implicadas na educação coletiva.

Aarão Pereira de Araújo Júnior, professor do Instituto Federal de Educação, Ciência e Tecnologia da Paraíba (João Pessoa/PB, Brasil) e Robson Xavier da Costa, 


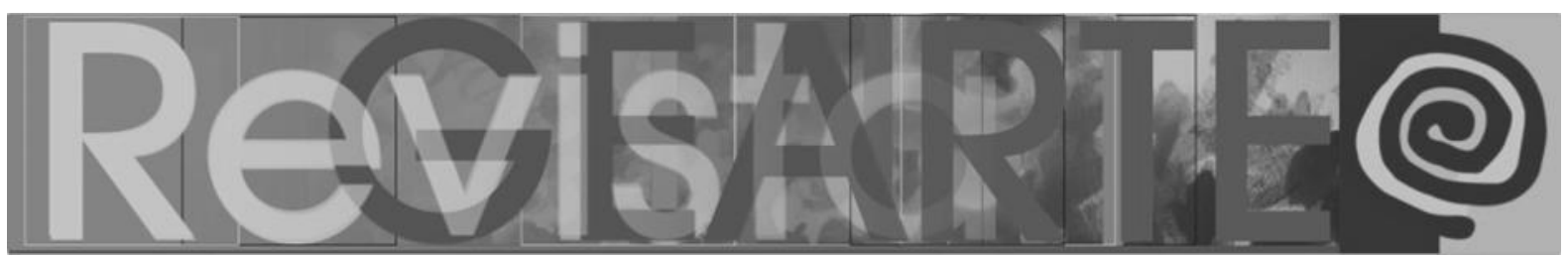

professor da Universidade Federal da Paraíba (João Pessoa/PB, Brasil), no texto Artes Visuais e Design de Interiores: iconografia e o conceito de projeto, estudam o impacto das artes visuais na formulação do conceito de projeto nas disciplinas do eixo central do Curso Superior de Tecnologia em Design de Interiores, do Instituto Federal de Educação, Ciência e Tecnologia da Paraíba (CSTDI/IFPB), analisando a experiência do minicurso experimental desenvolvido no IFPB em 2017, avaliando a utilização dos elementos da linguagem visual aplicados ao conceito de projeto para design de interiores.

Lislaine Sirsi Cansi, da Universidade Federal de Pelotas (Pelotas/RS, Brasil), aborda o ensino da arte e do design em diálogos com a história, no artigo $O$ ensino das Artes Visuais e do Design: o campo da História como estratégia de pesquisa, especialmente a história cultural, seus métodos e teorias, a partir de pesquisas desenvolvidas no Programa de Pós-graduação em Artes Visuais da UFPel, cujo interesse em abordagens de ensino via educação estética e sensível, possibilitou reflexões e aproximações com o campo do Design. Assim, a autora apresenta as práticas de pesquisadores utilizadas ou aplicadas ou pensadas para a sala de aula como preocupação teórico-metodológica.

No artigo Uma estética da violência presente no Cinema Brasileiro e o apagamento de mulheres negras nas produções audiovisuais as autoras Bárbara Cezano Rody, da Universidade Federal de Pelotas (Pelotas/RS, Brasil) e Larissa Patron Chaves, professora da Universidade Federal de Pelotas (Pelotas/RS, Brasil), questionam a presença de mulheres negras cineastas na historiografia do cinema brasileiro. Iniciam suas investigações e reflexões a partir de questionamentos acerca da visibilidade dos corpos negros, cujas dificuldades de encontrar pistas dessa atuação, são atribuídas a uma claridade hegemônica presente no cinema brasileiro. Assim, a busca das autoras por narrativas historiográficas que possibilitem identificar cineastas negras e também o cinema negro no Brasil, propõe ultrapassar uso de fontes e recortes historiográficos considerados restritivos a tal visibilidade. 


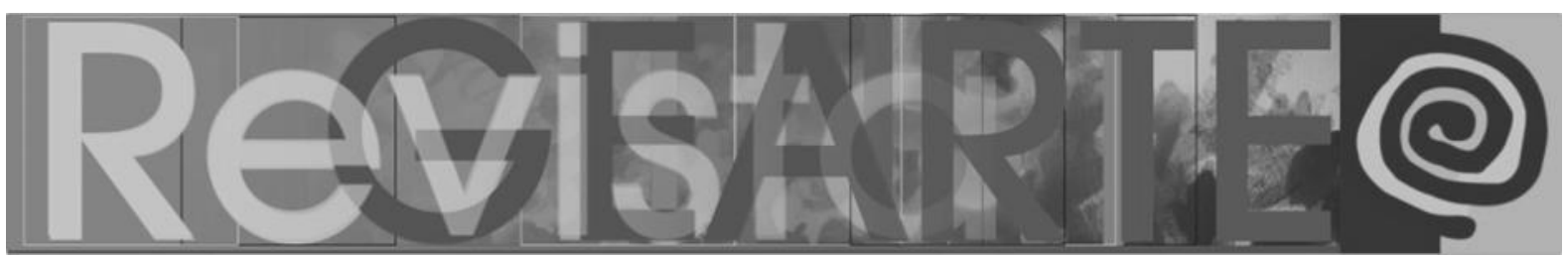

Micaelle Lages Lucena, da Universidade Federal da Paraíba (João Pessoa/PB, Brasil) e Isabella Chianca Bessa Ribeiro do Valle, professora da Universidade Federal da Paraíba (João Pessoa/PB, Brasil), propõem compreender o ensino das artes visuais e a produção cinematográfica como ferramenta política de valorização da identidade a partir de ações realizadas como projeto de extensão universitária na UFPB. As reflexões das autoras são apresentadas no artigo CinEducar e Partejar Potiguara: o ensino do cinema para mulheres indígenas como ferramenta de (r)existência, no qual o desafio de repensar os distanciamentos adequados entre quem pesquisa, fotografa ou documenta e quem é pesquisado, fotografado e documentado mescla-se ao desafio de apresentar e representar a realidade a em sua complexidade de olhares.

Pilar Pérez Camarero e María Ángeles Alegre del Rey, professoras da Universidad Autónoma Madrid (Madri, Espanha), no artigo Proposta colaborativa com futuros professores da educação infantil. Lanches temáticos, séries, performances e instalações as autoras apresentam experiência de treinamento realizada com futuros professores de educação artística na UAM. Fruto de um projeto de inovação que fez uso de investigação/ação transformadora do ocorrido nas aulas, por meio da observação e elaboração de um caderno de campo, cujos registros potencializam a sensibilização, a reflexão e as ações de conscientização do pensamento artístico.

O ensaio visual Nós, apresentado por Júlio César Herbstrith, professor da Universidade Feevale (Novo Hamburgo/RS, Brasil) e Bruno Schilling, artista visual (Novo Hamburgo/RS, Brasil), nos coloca diante de murais saturados de cores remetendo à arte cinética e ao modernismo bauhausiano, nas construções formais, nos grids aparentes e nos deslocamentos colorísticos e visuais.

Apresentamos, ainda, a admirável, respeitosa e carinhosa homenagem de Ana Mae Barbosa, da Universidade de São Paulo e da Universidade Anhembi-Morumbi (São Paulo/SP, Brasil), ao arte/educador estadunidense Arthur Efland, professor da Universidade do Estado de Ohio, falecido aos 90 anos, que em seus escritos alertou 


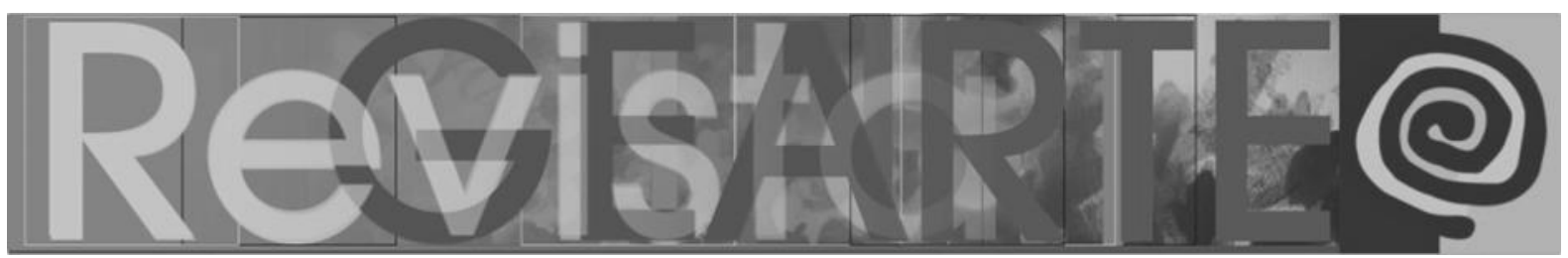

para importância das conexões entre o mundo da arte e a Educação Artística ensinada nas escolas.

Dificilmente propostas acadêmicas abordam as duas áreas de conhecimento (artes visuais e design) a partir dos seus pontos de interconexão, considerando os intersaberes necessários para a expansão do campo de conhecimento e produção de imagens na contemporaneidade. Convidamos @s leitor@s da Revista Gearte para dividir conosco os saberes sobre o ensino das artes visuais e design publicados neste número, visando estimular novos olhares sobre a inter-relação entre as duas áreas de conhecimento em seus múltiplos contextos.

\section{Referências}

DE CERTEAU, Michel. A invenção do cotidiano: artes de fazer. Trad. Ephraim Ferreira Alves. Petrópolis - RJ: Vozes, 1998.

DEWEY, John. Arte como experiência. Trad. Vera Ribeiro. São Paulo SP: Martins Fontes, 2010.

\section{Dr. Robson Xavier da Costa ${ }^{1}$}

(Universidade Federal da Paraíba — UFPB, João Pessoa/PB, Brasil)

\section{Dra. Luciene Lehmkuhl²}

(Universidade Federal da Paraíba — UFPB, João Pessoa/PB, Brasil)

Organizadores do presente número

1 Artista visual, curador e professor/pesquisador em artes visuais. Doutor em Arquitetura e Urbanismo (PPGAU UFRN); Mestre em História (PPGH UFPB). Realizou Estágio Sanduíche na Universidade do Minho, Portugal e na Universidad de Granada - Espanha; Especialista em Educação Especial (CE UFPB); Licenciado em Educação Artística - Artes Plásticas (UFPB) e Pós-doutor pelo PGEHA MAC USP. Docente/Pesquisador no Departamento de Artes Visuais da Universidade Federal da Paraíba (UFPB) e nos Programas de Pós-Graduação em Artes Visuais (PPGAV UFPB/UFPE - Atual Coordenador) e de Computação, Comunicação e Arte (PPGCCA UFPB). Membro da ABCA, da ANPAP e da FAEB.

2 Historiadora e professora/pesquisadora em artes visuais. Doutora, Mestre e Graduada em História pela Universidade Federal de Santa Catarina (UFSC) e Graduada em Educação Artística - artes plásticas - pela Universidade do Estado de Santa Catarina (UESC). Realizou estágio sanduíche na Universidade Nova de Lisboa e estágio pós-doutoral na EHESS/Paris. Foi Docente/Pesquisadora na Universidade Federal de Uberlândia (UFU), atuando na graduação e pós-graduação. Atualmente é Docente/Pesquisadora Associada na Universidade Federal da Paraíba no Curso de Design, Campus IV/Rio Tinto e professora permanente no Programa Associado de Pós-graduação em Artes Visuais - PPGAV - UFPB/UFPE. Membro do CBHA. 